Diversity of Research in Health Journal / Revue de la Diversité de la Recherche en Santé

Vol 4, January / Janvier 2021 - ISSN: 2561 -1666 DOI : 10.28984/drhj.v4i2.323

\title{
Exploring the Benefits of an Arts-Based Mindfulness Group Intervention for Teachers, University Students, and Women Survivors of Intimate Partner \\ Violence
}

\section{Coholic ${ }^{1}$ A. Hardy P. Goeldner \& S. McMahon \\ DRHJ/RDRS 2021, 4, pp.17-32}

Diana Coholic, Ph.D., RSW

Full Professor, dcoholic@laurentian.ca

School of Social Work, Faculty of Health,

Laurentian University, Sudbury (ON), Canada.

Amanda Hardy, B.Ed., MA

Elementary school teacher, Rainbow District School Board, ak_hardy@laurentian.ca

School of Rural and Northern Health, Faculty of Health

Laurentian University, Sudbury (ON), Canada.

Patricia Goeldner, B.Ed., MSW, RSW

Social worker, Rainbow District School Board, goeldnp@ rainbowschools.ca

School of Social Work, Faculty of Health,

Laurentian University, Sudbury (ON), Canada

Stephanie McMahon, BSS, MSW, RSW

Law student and private practitioner, smcmahon@laurentian.ca

School of Social Work, Faculty of Health,

Laurentian University, Sudbury (ON), Canada.

\begin{abstract}
Mindfulness-based interventions (MBIs) teach practices that encourage the development of present moment awareness through paying attention on purpose and non-judgmentally to one's experiences, feelings, thoughts, and behaviours. We describe three graduate student research thesis projects that explored the suitability and benefits of an arts-based MBI with three different populations; teachers, university students, and women survivors of intimate partner violence. These three populations have been identified as experiencing heightened levels of stress and in need of resilience building supports. All three projects were qualitative pilot studies that explored whether participants would experience increased understanding and development of mindfulness-based skills, and improved coping with stress through participating in the program. Pre- and post-MBI group interviews were conducted, and interview data were analyzed using thematic analysis. Across the three projects, the student researchers found selfreported benefits with no adverse effects. Developing mindfulness-based skills helped the participants to build their self-awareness/understanding, which in turn helped to develop emotion regulation. These changes are consistent

${ }^{1}$ Correspondence concerning this article should be addressed to Diana Coholic, School of Social Work, Laurentian University, Sudbury, Ontario, Canada P3E 2C6. 705-675-1151, ext. 5053. Email: dcoholic@laurentian.ca
\end{abstract}


with our understanding of how MBIs can build people's capacities to make conscious choices about their feelings rather than reacting to emotional triggers. Improved coping with stress was also reported in all three projects. Developing present-moment awareness and mindfulness can help people appreciate life's moments, and cope better with daily life stressors. Also important was the growth of self-compassion and acceptance. The results are promising and indicate that further exploration with these populations is warranted. Future research could explore an arts-based approach to facilitating mindfulness with larger numbers of participants and using control and/or comparison groups.

Keywords: mindfulness, stress, arts-based, teachers, post-secondary, intimate partner violence

\section{Résumé}

Les interventions fondées sur la pleine conscience enseignent des pratiques qui encouragent la conscience du moment présent, tout en prêtant une attention délibérée et sans jugement à ses expériences, sentiments, pensées et comportements. Nous décrivons trois projets de thèse de recherche d'étudiants diplômés qui ont exploré la pertinence et les avantages d'une intervention fondés sur les arts avec trois populations différentes; les enseignants, les étudiants universitaires et les femmes survivantes de violence conjugale. Ces trois populations ont été identifiées comme éprouvant des niveaux de stress accrus et ayant besoin de soutien et renforcement des capacités de résilience. Les trois projets étaient des études pilotes qualitatives qui cherchaient à déterminer si les participants développent une meilleure compréhension, de nouvelles capacités fondées sur la pleine conscience et une meilleure gestion du stress en participant au programme. Des sondages de groupe précédant et suivant l'intervention ont été menés. Ensuite, les données ont été analysées à l'aide d'une analyse thématique. Dans les trois projets, les étudiants chercheurs ont trouvé plusieurs avantages sans effets indésirables. Le développement de capacités fondées sur la pleine conscience a aidé les participants à développer leur conscience et compréhension de soi, ce qui à son tour a aidé à développer la régulation des émotions. Ces changements sont cohérents avec notre compréhension de la façon dont ces interventions peuvent renforcer les capacités des gens à faire des choix conscients au sujet de leurs sentiments plutôt que de réagir émotionnellement. Une meilleure gestion du stress a également été signalée dans les trois projets. Développer la pleine conscience du moment présent peut aider les gens à apprécier les moments de vie et d'atteindre le niveau de résilience nécessaire pour faire face au stress de la vie quotidienne. L'augmentation de compassion et de l'acceptation de soi était également importante. Les résultats sont prometteurs et justifient une recherche plus approfondie avec ces populations. Des recherches futures pourraient explorer une approche fondée sur les arts pour faciliter la pleine conscience avec un plus grand nombre de participants et en utilisant des groupes de contrôle et/ou de comparaison.

Mots clés : pleine conscience, stress, méthodologies artistiques, enseignantes, postsecondaires, violence entre partenaires intimes

\section{Introduction}

Exploring the Benefits of an Arts-Based Mindfulness Group Intervention for Teachers, University Students, and Women Survivors of Intimate Partner Violence.

Mindfulness-based practices and concepts promote activities and a way of being in the world that encourages present moment awareness through paying attention on purpose and nonjudgmentally (Kabat-Zinn, 2013). Thus, the goals of mindfulness-based interventions (MBIs) include becoming more aware of one's moment-to-moment stream of consciousness and to accept these experiences without judgment. Mindfulness Based Stress Reduction (MBSR) is the most studied MBI. It was developed in the late 1970s by Dr. Jon Kabat-Zinn and colleagues to support the treatment of adults dealing with chronic pain and illness, stress, and anxiety (KabatZinn, 2013). MBSR follows a structured curriculum over 8 weeks in 2.5-hour weekly sessions, plus a full-day session near the end of the program. Weekly sessions include activities such as body scans; mindful breathing, walking, sitting and eating; and yoga movements.

Most other MBIs have been adapted from MBSR, for example, Mindfulness Based Cognitive Therapy (MBCT), which focuses on symptoms of recurring depression (Segal, 
Diversity of Research in Health Journal / Revue de la Diversité de la Recherche en Santé Vol 4, January / Janvier 2021 - ISSN: 2561 -1666 DOI : 10.28984/drhj.v4i2.323

Williams \& Teasdale, 2012). In MBCT, cognitive behavioural therapy exercises are used to help change negative thinking patterns. These two MBIs, as well as others such as Mindful SelfCompassion (Centre for Mindful Self-Compassion, 2017), Dialectical Behaviour Therapy (Linehan, 1993), and Acceptance and Commitment Therapy (Hayes, Strosahl, \& Wilson, 1999), have been studied extensively with adult populations showing diverse benefits such as decreased stress and anxiety, improved mood and coping skills, and more (Fjorback, Arendt, Ornbol, Fink, \& Walach, 2011). With increased understanding of one's feelings and thoughts, a person can make better choices regarding their emotional expression, which can lead to improved coping and functioning (Teper, Segal, \& Inzlic, 2013). Mindfulness can also help a person view negative thoughts as passing events rather than valid reflections of reality, and it can promote flexible responses as opposed to becoming stuck in anxiety or ruminating (Ciarrochi, Kashdan, Leeson, Heaven, \& Jordan, 2011).

Since 2005, the first author has led a research team studying the benefits of an arts-based MBI called Holistic Arts-Based Program or HAP, mainly with marginalized child and youth populations. HAP is innovative as it was developed from research with children living in foster care, and contextualizes the teaching of mindfulness-based practices and concepts in arts-based methods such as drawing, painting, working with clay and sand, collage, music, and more (Coholic, 2019). HAP is a 12-week program held one time per week in 2-hour group sessions. The goals of HAP include learning mindfulness, improving self-awareness, developing selfcompassion and empathy, and shoring up strengths. Arts-based methods denote the application of art therapy techniques and are used in a variety of fields including social work and education. Art therapists have argued for connections between using art and improving aspects of resilience since the 1970s (Malchiodi, 2007). Indeed, in a recent scoping review, we found that researchers justified using arts-based methods because they are both effective and relevant especially for marginalized populations (Coholic, Schwabe, \& Lander, 2020). Arts-based methods are highly engaging, enjoyable, and can help people express their thoughts and feelings in ways that are less intimidating. The use of arts-based methods also makes learning mindfulness accessible and successful, particularly for participants who might struggle with more traditional ways of practicing that demand the ability to sit still, focus, and engage with homework (Coholic, Oystrick, Posteraro, \& Lougheed, 2016).

In this paper, we discuss three graduate student thesis research projects in which the student researchers tested the feasibility, suitability, and benefits of HAP with three different adult populations: teachers, Laurentian University concurrent education students, and women survivors of intimate partner violence (IPV). These three groups have been identified as experiencing heightened levels of stress and in need of resilience building supports and services. We hypothesized that they could all benefit from learning mindfulness-based practices and concepts by way of participating in HAP. While teachers and university students have been the subject of some MBI research (Galante et al., 2018; Kerr, et al., 2017; Meiklejohn et al., 2012; Smith \& Jelen, 2016), this area of inquiry is emergent. Also, there is scant research exploring MBIs with women survivors of IPV especially within a shelter environment (Dutton, Bermudez, 
Diversity of Research in Health Journal / Revue de la Diversité de la Recherche en Santé Vol 4, January / Janvier 2021 - ISSN: 2561 -1666 DOI : 10.28984/drhj.v4i2.323

Matas, Majid, \& Myers, 2013; Kimbrough, Magyari, Langenberg, Chesney, \& Berman, 2010). The three research projects discussed in this paper had similar research questions, used the same methodology, and found convergent results. We provide an overview of each project with discussion about the implications of this work for using an arts-based approach to facilitating MBIs for the purposes of supporting well-being.

\section{Three Graduate Student Thesis Research Projects}

In Study 1, the second author explored the effects of participating in HAP on teachers' stress, mindfulness, and teaching practices (Hardy, 2019). HAP was facilitated with two small groups of mostly teachers employed by a northeastern Ontario English school board. It is well documented that teachers experience high levels of stress (Froeses-Germain, 2014). Workload, student academic challenges, time pressures (Taylor, Harrison, Haimovitz, Oberle, Thomson, Schonert-Reichl, \& Roser, 2016), relationships with administration and colleagues, poor working conditions, and work-life imbalance (Antoniou, Ploumpi, \& Ntalla, 2013; Gold \& Roth, 2013; Kyriacou, 2001; Napoli, 2004) are amongst the frequently cited sources of teacher stress. Also, teachers' reports of stress are strongly correlated with challenging student behaviours (Pang, 2012; Yoon, 2002). However, teachers who are trained in mindfulness have been found to have increased emotional awareness, empathy, and compassion, the ability to listen more effectively, and a better ability to manage classroom behaviours, and maintain supportive relationships with students (Meiklejohn et al., 2012). Moreover, MBIs that address teacher stress as well as provide them with accessible activities to teach mindfulness skills and concepts to their students may help to decrease their own stress and support their students' well-being. The research question in Study 1 was: How does participating in HAP effect teachers' self-reported stress levels, mindfulness skills, and teaching practices?

In Study 2, the third author explored the effects of HAP participation with two small groups of concurrent education university students (Grynspan, 2018). Student well-being is a growing concern as university students reveal alarmingly high rates of stress-related challenges such as anxiety and depression (American College Health Association, 2016). A national survey conducted with 41 Canadian postsecondary institutions found that $44 \%$ of students reported feeling so depressed that it was difficult to function and $65 \%$ of students reported overwhelming anxiety (up from 58\% in 2013) (American College Health Association, 2016). A critical issue for post-secondary institutions is how to implement effective approaches to support students' mental health and well-being. We hypothesized that through participating in HAP, concurrent education students could be helped to manage their stress while also gaining knowledge that they could bring to their future teaching experiences. The research question in Study 2 was: Does participating in HAP improve education students' skills in mindfulness, and change their perceptions of the stress they are experiencing? What are their experiences in HAP?

In Study 3, the fourth author hoped that by participating in HAP, women who have escaped IPV would be helped to build aspects of resilience such as self-awareness, selfcompassion, and coping skills (McMahon, 2019). Meeting these women's needs is a persistent 
concern in shelters across the country as women experience many stress-related challenges after escaping abuse including post-traumatic symptoms such as anxiety, depression, and low selfesteem (Tutty, 2006). The annual national report of YWCA Canada (Tutty, 2015) acknowledged that women's shelters require innovative, cost-effective supports that use a trauma-informed perspective to meet the diverse needs of their residents. The research question was: Does participating in HAP improve women survivors' of IPV skills in mindfulness, and change their perceptions of the stress they are experiencing? What are the experiences of women survivors of IPV in HAP?

\section{Methodology}

The main thrust of all three projects was qualitative, as they were pilot projects exploring the feasibility, acceptability, and benefits of participating in HAP. The methodology was framed within a social constructivist framework, which understands that different people experiencing the same situation construct meaning in different ways based on their personal interpretations, which are influenced by their past experiences. Individuals create understanding of the world through interactions within their groups (Crotty, 1998). HAP utilizes a strengths-based approach and consists of three foundational underpinnings; group work, arts-based methods, and mindfulness. A strengths-based approach values the experiences and perspectives of individuals while group work provides opportunities for members to support one another and create new understandings together. Arts-based methods enable participants to express themselves in a nonthreatening manner, creating a starting point for dialogue and reducing the extent to which the researcher holds power within the group (Blodgett et al., 2013). The flattening of the power imbalance between facilitator(s) and participants increases the co-construction of meaning and new understandings amongst the entire group. Thus, the strengths-based and arts-based approach, and the use of social group work in HAP, support the framework/epistemological approach.

\section{Participants}

Purposive and convenience sampling was used, in which participants were selected based on their experiences with the key concepts (Creswell, 2013). Study 1 facilitated HAP with two different groups of eight participants each. One group included one social worker, one educational assistant, and six teachers (one taught elementary school; the others worked at the same high school). The second group included one educational assistant, two high school teachers, and five elementary school teachers. The mean age of the participants was 44 years, and they had on average 16 years of experience. Eleven of the 16 participants completed HAP and participated in post-HAP interviews. Of the five who did not complete the program, two reported that they had overcommitted their time and would consider participating in the future; one withdrew due to medical reasons; one withdrew due to caregiving responsibilities; and one dropped out for unknown reasons. Thus, Group One ended with six participants and Group Two with five. Their primary motivation for participating in HAP was to learn mindfulness-based practices for professional purposes. 
Study 2 facilitated HAP with two different groups comprised of five concurrent education students in each group plus one additional non-education university student per group generating two groups of six participants each. Of the 12 students, 11 were female and one was male ranging in age from 18 to 21 years old with a mean age of 20 years. One participant withdrew after the first session citing involvement in an excess of extracurricular activities. Another two participants attended four and five out of the 12 sessions respectively and did not complete the program. We concluded the study with seven female participants in total. The education students attributed stressors as the primary motivation for HAP participation. Examples of these stressors included negative thinking, finances, academics, social life, employment, procrastination, and parental demands. Another motivation for participation was to learn mindfulness skills and concepts to bring into the classroom, and an opportunity to enhance employability.

In Study 3, two different HAP groups were facilitated with eight and six participants respectively. These 14 women ranged in age from 24 to 77 years old with a median age of 46 years. Due to attrition, complete data was collected from 10 participants. Of the initial eight participants who started group one, one participant withdrew stating that she found the other women's feelings too difficult to listen to. Group two had six women begin the program but one participant dropped out due to chronic pain. Another participant did not return after she transitioned out of the shelter, and a third participant dropped out due to a conflict outside of the group with another participant. The women stated that their motivation for participation was to address mental health challenges (e.g., feelings of anxiety and depression), and well-being by reducing stress (e.g., ex-partners, court processes, dealing with child welfare, and transitioning into housing).

\section{Facilitation of HAP and Group Interviews}

HAP sessions took place after the school day ended in two schools (Study 1), in the first author's research lab at Laurentian University (Study 2), and at the local transition house/shelter (Study 3). Every HAP group was co-facilitated by the graduate student researchers. Research assistants (RAs) co-facilitated HAP with the graduate student researchers. The RAs were trained in HAP facilitation and were supervised by the first author, which helped to ensure fidelity in HAP facilitation and delivery. Also, student RAs familiar with HAP and working under the supervision of the first author conducted the pre- and post-HAP group interviews for the graduate student researchers.

A group interview approach was used in all three projects as it mirrored the group process and was a viable option given available resources. The pre-HAP interviews were conducted prior to the first HAP session and these were under an hour in duration. Open-ended questions were asked that focused on participants' understanding of mindfulness and their current stressors. Post-HAP group interviews focused on the participants' experiences in HAP, their perceptions of benefits and learning, challenges they experienced, and thoughts regarding program improvements. 
Diversity of Research in Health Journal / Revue de la Diversité de la Recherche en Santé

Vol 4, January / Janvier 2021 - ISSN: 2561 -1666 DOI : 10.28984/drhj.v4i2.323

\section{Qualitative Data Analysis}

Pre- and post-HAP group interview data were transcribed and analyzed using a thematic analysis process as originally outlined by Braun and Clarke (2006). Thematic analysis is commonly used for qualitative analysis and involves the identification, analysis, and reporting of themes across datasets. According to Braun and Clarke (2006), thematic analysis explains large portions of the data and is a reflexive process requiring the researcher to reflect on how the data is being conceptualized. There are six phases to the process beginning with familiarizing yourself with the data by listening to the audio-recorded interviews and transcribing them. Initial coding of the interviews began by noting patterns in the data. Step three involved looking for similarities amongst the initial codes for the purposes of forming themes. These initial themes were reviewed and labelled, and then revised and refined through a continual process of personal reflection, feedback from colleagues, research assistants, and the first author. Naming, describing, and refining the themes led to the next step of extracting compelling examples to support each theme and further refining of the theme names. Transcriptions were also re-read at this stage. In an effort to ensure the selected extracted examples were the most compelling and accurately described the intended meaning of the participants, discussion was had with the interviewers about the themes generated and the examples that were selected.

\section{Results}

In all three projects, similar self-reported benefits were experienced by the participants: (1) they deepened their understanding about mindfulness and developed self-awareness of thoughts and feelings, (2) they found the arts-based activities helpful in that these methods provided a way to learn and practice mindfulness in accessible and enjoyable ways, and helped them understand and express their feelings with non-judgment, (3) they improved their emotion regulation and abilities to cope with stress, which benefitted both their personal lives and professional practices, and (4) they experienced social inclusion and normalization.

\section{Study 1 HAP with Teachers}

In Study 1, many of the teachers shared that their participation in HAP helped them learn and practice mindfulness in their personal and professional lives. They also indicated that postHAP, they felt better equipped to manage stress, and they had a strong desire and increased capacity to bring mindfulness activities to students. First, the participants learned a more accurate and comprehensive understanding of mindfulness that included concepts such as selfawareness, non-reactivity, openness, acceptance, non-judgment, and self-compassion. They demonstrated an understanding that mindfulness practice changes your way of being in the world. As one participant explained: "I catch myself much like Holly...catching that ray of sun, when it's been cloudy all day and just really soaking in that moment. Or out walking the dog and I'm really just enjoying the sound of the snow or the feel of my snowshoes going through the ... crust or the birds outside..." (Hardy, 2019, p. 65).

Second, the participants identified personal and professional benefits of participating in

HAP. Most of the participants explained how increased self-awareness helped them improve 
Diversity of Research in Health Journal / Revue de la Diversité de la Recherche en Santé Vol 4, January / Janvier 2021 - ISSN: 2561 -1666 DOI : 10.28984/drhj.v4i2.323

emotion regulation, that is, more conscious, thoughtful responses to daily situations. Professionally, becoming less reactive, cultivating gratitude, and dealing with stressful situations in a calm manner fosters the development of positive relationships between teachers and students, and can also model for students a mindful way of being and positive stress management techniques (Jennings, 2015). Teachers who are self-aware, non-judgmental, and mindful are better able to meet classroom demands (Hahn \& Weare, 2017). For example, one participant described how developing a beginner's mind, curiosity about, and appreciation for her students, and embodying mindfulness impacted the learning environment: "[HAP] definitely benefited me personally to stay calm. Even when I go to work now, every day is a new day...we have a lighter mood [in the classroom]" (Hardy, 2019, p. 72). Indeed, teacher presence can be developed through the embodiment of mindfulness (Miller, 2007). Teacher presence is authentic, attentive awareness of students and the environment, and enables teachers to better deal with the changing needs of their students with patience and compassion in an open and receptive manner (Rodgers \& Raider-Roth, 2006).

Third, the participants stressed the usefulness of learning by way of arts-based methods. They enjoyed HAP as it created a fun and safe place for them where they could be open and authentic while learning new and challenging concepts and practices. Elizabeth spoke to the playful nature of the arts-based methods reminding her of her younger self. She stated, "I really enjoyed the collage...It sparked this memory of how much I really loved collaging for like 10 years of my life...brought back a little childhood like, oh ya, this is friggin' fun" (Hardy, 2019, p. 61). The purposeful use and application of social group work methods was also noted as a positive aspect of HAP. For instance, some participants expressed that they appreciated the opportunity to connect with other educators in a comfortable and relaxed atmosphere that created a sense of trust, fostered positive connections, and promoted a sense of normalcy.

\section{Study 2 HAP with Concurrent Education Students}

In Study 2, students' experiences in HAP helped them to manage their stress and offered them activities to take into future teaching experiences. First, the students increased their selfawareness and understanding of mindfulness. As one participant shared:

I didn't know what it [mindfulness] was before I started, I was very confused...mindfulness...is to me, knowing your emotions, knowing your feelings, knowing your dreams...the biggest part of mindfulness...I suppose it would be really getting to know myself (Grynspan, 2018, p. 61).

In turn, increased self-awareness led to improved emotion regulation where participants could make choices about feelings and respond more effectively rather than react: "Mindfulness really helped me figure out how I'm feeling...what triggered that emotion... how I can prevent it or not let myself go into a downward spiral" (Grynspan, 2018, p. 65). These improvements were linked with better coping in daily life and reduced feelings of distress.

Second, as in Study 1 described above, the arts-based nature of HAP was noted as beneficial. The students explained that the creative methods helped make mindfulness concepts accessible, offered opportunities for self-expression, guided future applications, increased self- 
Diversity of Research in Health Journal / Revue de la Diversité de la Recherche en Santé Vol 4, January / Janvier 2021 - ISSN: 2561 -1666 DOI : 10.28984/drhj.v4i2.323

understanding, and promoted an enjoyable experience. They described how the art-based mindfulness activities provided opportunities for emotional understanding and expression, and provided ideas pertaining to future applications in teaching:

I want each [of my students] to have a plastic bottle and then I would have beads in the classroom that represented emotions and then they could just go to their bottles whenever they want and put in their beads...then as the teacher, I would want to go through their bottles and see what my kids [students] were feeling (Grynspan, 2018, p. 88).

There were also benefits that were connected to the group work. The participants experienced normalization, social inclusion, acceptance, and belonging.

\section{Study 3 HAP with Survivors of IPV}

In Study 3, the women's experiences learning mindfulness mirrored the results described above. They experienced benefits from gaining skills in mindfulness and from engaging with arts-based methods within social group work. First, the participants' self-awareness developed and they described how they became increasingly aware of their thoughts and feelings throughout participation in the program. Several HAP activities invited participants to reflect on thoughts or feelings experienced during the activity and this practice of reflection encouraged present moment awareness and fostered self-awareness. As one participant said:

I shed a lot of tears in this room, and I'm not ashamed to shed my tears or share my feelings because bottling them up does not prove anything and it doesn't benefit us in any way...[HAP] made me more mindful of how I'm feeling and being more aware of myself... I'm doing things to make every day better (McMahon, 2019, p. 95).

Second, through the repeated opportunities for self-expression, self-exploration, and group discussions, the participants developed a deeper understanding of their thoughts and feelings that helped them regulate their behaviours (emotion regulation). Acceptance of feelings was also evident as feelings were met with less judgement. Awareness, emotion regulation, and acceptance are common outcomes of participation in an MBI. For the women living in the transition house, negative self-judgment was one of the most difficult but important things to change.

Third, the participants shared that HAP participation helped them reduce their stress. One woman explained: "[HAP] was the thing I looked forward to every week; it was that thing that kept me going. That one week I had to miss, that was hard. It's over, and I know I'll miss it; the program was valuable." Another woman stated "[HAP] helped to make sense of my emotions, which helped reduce my stress because I could understand what I was feeling” (McMahon, 2019, p. 103).

Fourth, regarding the arts-based methods, the women explained how these methods promoted successful learning because they were accessible and engaging, and provided a handson, enjoyable, creative way of learning. One participant pointed out that the arts-based methods were playful and that learning with joy and positivity was refreshing in a shelter environment where community living can be stressful: "The playful component of art activities made it more 
Diversity of Research in Health Journal / Revue de la Diversité de la Recherche en Santé Vol 4, January / Janvier 2021 - ISSN: 2561 -1666 DOI : 10.28984/drhj.v4i2.323

livable...more tolerable to be here while you're still trying to plan and re-build your life" (McMahon, 2019, p. 109). Moreover, one participant described how arts-based methods helped her express her thoughts and feelings, build her self-esteem, and provided her with a sense of control in her healing process:

...drawing or painting helped me express what I'm feeling and discover what I like. It also gave me motivation, especially the envelopes where we leave positive notes for each other. Before I always used to tell myself I'm not a good person, I am miserable, I am bad, I am all these negative things. But whenever I read those messages, I feel good about myself. Because I have a hard time expressing my feelings, I like those activities. The arts-based thing helped me because through the art I get to choose what I want to add or what I want to be (McMahon, 2019, p. 113).

Fifth, engaging in a group with other women survivors of IPV was important because the group work provided opportunities for peer support, feelings of normalization, and social inclusion. As one participant said, "As women, we are givers of all the love and all the kindness we offer to everybody else...in the [HAP] it was nice to have a place to get some of that back and see all the positive things within yourself. I just bloomed in everything I did in here" (McMahon, 2019, p. 132). For women experiencing IPV, the opportunity to experience the normalization of their experiences is important (Herman, 2015) because linking one's experiences to other women's stories can provide comfort and reduce shame. The process of identifying similar experiences and feelings can build connections and lessen social isolation (Tesh, Learman, \& Pulliam, 2015).

\section{Discussion}

All three projects described in this paper found self-reported benefits for the participants of HAP with no reported adverse effects or challenges. Developing mindfulness-based skills helped the participants to increase their self-awareness and understanding which in turn helped to build emotion regulation. The development of emotion regulation is consistent with our understanding of how MBIs can build people's capacity to make conscious choices about their feelings and thoughts rather than reacting to emotional triggers (Teper, Segal, \& Inzlicht, 2013). Feelings of stress were also lessened as reported in all three projects. Developing presentmoment awareness and mindfulness can help people appreciate life's moments, and cope better with daily life stressors (Kabat-Zinn, 2013). Learning self-compassion and acceptance as opposed to negative self-judgment was also important for all of the participants. Mindfulnessbased concepts can help people understand that approaching our feelings and thoughts with curiosity and acceptance is necessary for positive change. Judging our feelings and thoughts keeps us stuck and is a roadblock to self-understanding and growth (Germer, 2009).

While all three projects found personal benefits, in Study 1, professional benefits were also reported. As described earlier in this paper, teachers who are less stressed and more mindful are more present, better able to cope with the demands of the classroom, and better equipped to offer mindfulness training to their students. When teachers connect, empathize, and build 
relationships with their students they create optimal learning conditions (Froeses-Germain, 2014). HAP helped the teacher participants build teacher presence and also offered them a variety of arts-based activities that they could use within the school setting. In fact, most of the teachers indicated that they had begun incorporating some mindfulness activities with their students, while others indicated the feasibility of doing so in the future. Similarly, the student participants in Study 2 indicated that they had ideas regarding how to bring some of the HAP activities to their future teaching practices.

The participants in all three of the projects affirmed that learning mindfulness-based practices and concepts using arts-based methods was enjoyable, relevant, and made this learning accessible and successful. Previous researchers supported the use of arts-based methods as aids in increasing self-understanding and self-expression (Huss \& Sela-Amit, 2018; McNiff, 2008). Creative approaches to facilitating MBIs are emergent but make sense for various reasons, including the effectiveness of the methods and their ability to engage participants in a helping process. Typically, in HAP, our rates of attrition have been low, which was reflected in these three projects. Fun is not an adjective often used to describe traditional MBIs; however, learning through hands-on enjoyable activities makes HAP more accessible to some people compared with more traditional practices. As one student participant explained:

If I had only done meditation and Tai Chi I would have went crazy...I have ADHD and can't focus at the best of times...when I'm doing art, I can sit down and really immerse myself into what I'm doing which is...what it's all about...the mindful part...trying to bring yourself into what you're experiencing instead of putting it on the back burner (Grynspan, 2018, p. 85).

The arts allow individuals symbolic and visual forms of expression in place of written or spoken language (Huss \& Sela-Amit, 2018).

In HAP, we also consciously use social group work practices to build mutual aid and group cohesion and belonging, which is not always the case with many MBIs even though most MBIs are facilitated in a group format (Coholic, Dano, Sindori, \& Eys, 2019). In all three projects, the participants described the group work as normalizing and supportive. According to Malekoff (2015), peer groups are distinctive as members may nudge, challenge, and encourage each other beyond the capacity of any facilitator. Especially for university students who may be absent from their families for the first time in their lives, and women leaving intimate partner relationships who may feel isolated and alone, group work may be particularly relevant and meaningful. As one student participant said, "Sometimes a lot of us were thinking the same thing, feeling the same thing, having the same emotions, and to do the group activities and see what we came up with was really, really cool" (Grynspan, 2018, p.78).

\section{Conclusion}

The three research projects discussed in this paper expanded our earlier work investigating HAP with marginalized young people by exploring the suitability and benefits of HAP with three different adult populations. While the results are promising and indicate that 
Diversity of Research in Health Journal / Revue de la Diversité de la Recherche en Santé Vol 4, January / Janvier 2021 - ISSN: 2561 -1666 DOI : 10.28984/drhj.v4i2.323

further exploration of HAP with adult populations is warranted, the three projects were pilot studies conducted with small numbers of participants. As a result, future research should explore the benefits of HAP with larger numbers of adult participants, and using control and/or comparison groups, which would enable us to conclude with more certainty that the reported benefits were based on HAP participation. Control groups could consist of wait list controls and comparison groups could be accomplished by comparing HAP with other MBIs such as MBSR or MBCT. Larger numbers of participants would also enable the collection and analysis of selfreport inventory data including scores on mindfulness, stress, well-being, and resilience.

We note that the results reported herein are consistent with our earlier research results (Coholic, Schinke, Oghene, Dano, Jago, et al., 2020; Coholic, Eys, McAlister, Sugeng, \& Smith, 2018; Coholic, \& Eys, 2016), and the results reported in the literature exploring MBIs with adult populations. Thus, based on our experiences and findings, we encourage other facilitators of MBIs to consider using creative approaches and a purposeful use of social group work to engage participants to encourage successful and enjoyable learning. An arts-based group work approach to facilitating mindfulness can be highly engaging, relevant, and effective. By using approaches that are accessible and enjoyable, diverse populations can learn mindfulness-based concepts and practices.

\section{References}

American College Health Association. (2016). American College Health Association-National College Health Assessment II: Canadian Reference Group Data Report Spring 2016. Hanover: MD. https://www.acha.org/documents/ncha/NCHAII\%20SPRING\%202016\%20CANADIAN\%20REFERENCE\%20GROUP\%20EXECUTI VE\%20SUMMARY.pdf

Antoniou, A. S., Ploumpi, A., \& Ntalla, M. (2013). Occupational stress and professional burnout in teachers of primary and secondary education: The role of coping strategies. Psychology, 4(03), 349. doi: 10.4236/psych.2013.43A051

Blodgett, A., Coholic, D., Schinke, R., McGannon, K., Peltier, D., \& Pheasant, C. (2013). Moving beyond words: Exploring the use of an arts-based in Aboriginal community sport research. Qualitative Research in Sport, Exercise and Health. doi:10.1080/2159676X.2013.796490

Braun, V., \& Clarke, V. (2006). Using thematic analysis in psychology. Qualitative Research in Psychology, 3(2), 77-101. doi :10.1191/1478088706qp063oa

Centre for Mindful Self-Compassion. (2017). What is self-compassion? https://centerformsc.org/learn-msc/

Ciarrochi, J., Kashdan, T., Leeson, P., Heaven, P., \& Jordan, C. (2011). On being aware and accepting: A one-year longitudinal study into adolescent well-being. Journal of Adolescence, 34, 695-703. doi: 10.1016/j.adolescence.2010.09.003 
Diversity of Research in Health Journal / Revue de la Diversité de la Recherche en Santé Vol 4, January / Janvier 2021 - ISSN: 2561 -1666 DOI : 10.28984/drhj.v4i2.323

Clarke, V., \& Braun, V. (2013). Teaching thematic analysis: Overcoming challenges and developing strategies for effective learning. The Psychologist, 26(2), 120-123. http://www.thepsychologist.org.uk/archive/archive_home.cfm?volumeID=26\&editionID $=222 \&$ ArticleID $=2222$

Coholic, D., Schwabe, N., \& Lander, K. (2020). A scoping review of arts-based mindfulness interventions for children and youth. Child \& Adolescent Social Work Journal. doi.org/10.1007/s10560-020-00657-5

Coholic, D., Schinke, R., Oghene, O., Dano, K., Jago, M., McAlister, H., \& Grynspan, P. (2020). Arts-based interventions for youth with mental health challenges. Journal of Social Work, 20 (3), 269-286. https://doi.org/10.1177/1468017319828864

Coholic, D. (2019). Facilitating Mindfulness: A Guide for Human Service Professionals. Whitby, ON: Northrose Educational Resources.

Coholic, D., Dano, K., Sindori, S., \& Eys, M. (Feb 4, 2019). Group work in mindfulness-based interventions with youth: A scoping review [Special issue]. Social Work with Groups. http://dx.doi.org/10.1080/01609513.2019.1571764

Coholic, D., Eys, M., McAlister, H., Sugeng, S., \& Smith, D. (2018). A Mixed Method Pilot Study Exploring the Benefits of an Arts-Based Mindfulness Group Intervention with Adults Experiencing Anxiety and Depression. Social Work in Mental Health, 16 (5), 556572. doi: 10.1080/15332985.2018.1449774

Coholic, D., Oystrick, V., Posteraro, J., \& Lougheed, S. (2016). Facilitating arts-based mindfulness group activities with vulnerable children: An example of nondeliberative social group work practice. Social Work with Groups, 39 (2-3), 155-169. doi:10.1080/01609513.2015.1050751.

Coholic, D., \& Eys, M. (2016). Benefits of an arts-based mindfulness group intervention for vulnerable children. Child \& Adolescent Social Work Journal, 33 (1), 1-13. doi:10.1007/s10560-015-0431-3.

Creswell, J. W., (2013). Qualitative inquiry \& research design: Choosing among five approaches. Los Angeles, CA: SAGE Publications

Crotty, M. (1998). The Foundations of Social Research: Meaning and Perspective in the Research Process. London: SAGE Publications Inc.

Dutton, M. A., Bermudez, D., Matas, A., Majid, H., \& Myers, N. L. (2013). Mindfulness-based stress reduction for low-income, predominantly African American women with PTSD and a history of intimate partner violence. Cognitive and Behavioral Practice, 20(1), 2332. doi: 10.1016/2011.08.003

Fjorback, L., Arendt, M., Ornbol, E., Fink, P., \& Walach, H. (2011). Mindfulness-based stress reduction and mindfulness-based cognitive therapy: A systematic review of randomized controlled trials. Acta Psychiatr Scand., 124, 102-119. doi:10.1111/j.1600-0447.2011.01704.x 
Diversity of Research in Health Journal / Revue de la Diversité de la Recherche en Santé Vol 4, January / Janvier 2021 - ISSN: 2561 -1666 DOI : 10.28984/drhj.v4i2.323

Froeses-Germain, B. (2014). Work-Life Balance and the Canadian Teaching Profession. [Canadian Teachers' Federation manuscript]. Canadian Teachers' Federation. https://eric.ed.gov/?id=ED546884

Galante, J., Dufour, G., Vainre, M., Wagner, A. P., Stochl, J., Benton, A., ... \& Jones, P. B. (2018). A mindfulness-based intervention to increase resilience to stress in university students (the Mindful Student Study): A pragmatic randomised controlled trial. The Lancet Public Health, 3(2), e72-e81. doi: 10.1016/S2468-2667(17)30231-1.

Germer, C. (2009) The mindful path to self-compassion. New York: Guilford Press.

Gold, Y., \& Roth, R. A. (2013). Teachers managing stress and preventing burn-out: The professional health solution. London: RoutledgeFalmer.

Grynspan, P. (2018). Finding yourself through art: Education students' experiences of an artsbased mindfulness group program. (Master's thesis, Laurentian University, Sudbury, Ontario). Retrieved from https://zone.biblio.laurentian.ca/handle/10219/3165

Hahn, T. N., \& Weare, K. (2017). Happy teachers change the world: A guide for cultivating mindfulness in education. Berkeley, CA: Parallax Press.

Hardy, A. (2019). Examining the effects of the holistic arts-based program on teachers' stress, mindfulness and teaching practices. (Master's thesis, Laurentian University, Sudbury, Ontario). Retrieved from https://zone.biblio.laurentian.ca/handle/10219/3298

Hayes, S. C., Strosahl, K., \& Wilson, K. G. (1999). Acceptance and Commitment Therapy: An experiential approach to behavior change. New York: Guilford Press.

Herman, J. L. (2015). Trauma and recovery: The aftermath of violence--from domestic abuse to political terror. New York: Basic Books.

Huss, E., \& Sela-Amit, M. (2018). Art in social work: Do we really need it? Research on Social Work Practice, 1-6. doi:10.1177/1049731517745995

Jennings, P.A., (2015). Mindfulness for teachers: Simple skills for peace and productivity in the classroom. New York: W. W. Norton \& Company.

Kabat-Zinn, J. (2013). Full catastrophe living: Using the wisdom of your body and mind to face stress, pain, and illness. New York: Bantam Books.

Kerr, S. L., Lucas, L. J., DiDomenico, G. E., Mishra, V., Stanton, B. J., Shivde, G., ... Terry, G. M. (2017). Is mindfulness training useful for pre-service teachers? An exploratory investigation. Teaching Education, 28(4), 349-359. doi: 10.1002/jclp.20624

Kimbrough, E., Magyari, T., Langenberg, P., Chesney, M., \& Berman, B. (2010). Mindfulness intervention for child abuse survivors. Journal of Clinical Psychology, 66(1), 17-33. doi: 10.1002/jclp.20624

Kyriacou, C. (2001). Teacher stress: Directions for future research. Educational Review, 53(1), 27-35. doi: 10.1080/00131910120033628

Linehan, M. M. (1993). Diagnosis and treatment of mental disorders. Skills training manual for treating borderline personality disorder. Guilford Press.

Malchiodi, C. (2007). The art therapy sourcebook. 2nd ed. New York, NY: McGraw-Hill. 
Diversity of Research in Health Journal / Revue de la Diversité de la Recherche en Santé Vol 4, January / Janvier 2021 - ISSN: 2561 -1666 DOI : 10.28984/drhj.v4i2.323

Malekoff, A. (2015). Group work with adolescents: Principles and Practice (3 ${ }^{\text {rd }}$ ed.,) New York, NY: Guilford Publications.

McNiff, S. (2008). Art-based research. In G. Knowles, \& A. Cole (Eds.), Handbook of the arts in qualitative research, (pp. 29-40). Thousand Oaks, CA: Sage Publications, Inc.

McMahon, S. (2019). Beyond shelter: The power of women stepping into connection. (Master's thesis, Laurentian University, Sudbury, Ontario). Retrieved from https://zone.biblio.laurentian.ca/handle/10219/3342

Meiklejohn, J., Phillips, C., Freedman, M. L., Griffin, M. L., Biegel, G., Roach, A., ... \& Saltzman, A. (2012). Integrating mindfulness training into K-12 education: Fostering the resilience of teachers and students. Mindfulness, 3(4), 291-307. doi:10.1007/s12671-0120094-5

Miller, J., P. (2007). The holistic curriculum ( $2^{\text {nd }}$ ed.,). Toronto, ON: OISE Press.

Napoli, M. (2004). Mindfulness training for teachers: A pilot program. Complementary Health Practice Review, 9(1), 31-42. doi:10.1177/1076167503253435

Pang, I. (2012) Teacher stress in working with challenging students in Hong Kong. Educational Research for Policy and Practice 11, 119-139. doi: 10.1007/s1067101191096

Rodgers, C. R., \& Raider-Roth, M. B. (2006). Presence in teaching. Teachers and Teaching, 12(3), 265-287. doi:10.1080/13450600500467548

Saltzman, A. (2012). Integrating mindfulness training into K-12 education: Fostering the resilience of teachers and students. Mindfulness, 3(4), 291-307. doi:10.1007/s12671-0120094-5

Segal, Z. V., Williams, J. M. G., and Teasdale, J. D. (2013). Mindfulness-based cognitive therapy for depression ( $2^{\text {nd }}$ ed.). New York: Guilford Press.

Smith, V., \& Jelen, M. (2016). Mindfulness Activities and Interventions that Support Special Populations. In K. Schonert-Reichl \& R. Roeser. (Eds). Handbook of mindfulness in education (pp. 171-190), New York: Springer.

Taylor, C., Harrison, J., Haimovitz, K., Oberle, E., Thomson, K., Schonert-Reichl, K., \& Roeser, R. W. (2016). Examining ways that a mindfulness-based intervention reduces stress in public school teachers: A mixed-methods study. Mindfulness, 7(1), 115-129. doi:10.1007/s12671-015-0425-4

Teper, R., Segal, Z. V., \& Inzlicht, M. (2013). Inside the mindful mind: How mindfulness enhances emotion regulation through improvements in executive control. Current Directions in Psychological Science, 22(6), 449-454. doi:10.1177/0963721413495869

Tesh, M., Learman, J., \& Pulliam, R. M. (2015). Mindful self-compassion strategies for survivors of intimate partner abuse. Mindfulness, 6(2), 192-201. doi: 10.1007/s12671 013-0244-4

Tutty, L. (2006). Effective Practices in Sheltering Women Leaving Violence in Intimate Relationships: Phase II Report 2006. Toronto: YWCA Canada. https://pathssk.org/wpcontent/uploads/2011/06/2006-Tutty-YWCA-EFFECTIVE-PRACTICES-INSHELTERING-WOMEN.pdf 
Diversity of Research in Health Journal / Revue de la Diversité de la Recherche en Santé Vol 4, January / Janvier 2021 - ISSN: 2561 -1666 DOI : 10.28984/drhj.v4i2.323

Tutty, L. (2015). Addressing the safety and trauma issues of abused women: A cross-Canada study of YWCA shelters. Journal of International Women's Studies, 16(3), 101-116. https://vc.bridgew.edu/jiws/vol16/iss3/8

Yoon J. S. (2002) Teacher characteristics as predictors of teacher-student relationships: Stress, negative affect and self-efficacy. Social Behavior \& Personality: An International Journal 30(5): 485-493. doi:10.2224/sbp.200.30.5.485 